\title{
HIV Western Blot
}

National Cancer Institute

\section{Source}

National Cancer Institute. HIV Western Blot. NCI Thesaurus. Code C95524.

An assay used to confirm the presence of anti-HIV1 antibodies in a blood samples.

Serum is incubated with vital protein that have been gel separated and affixed to a

membrane. The test is considered positive if two or more proteins react and

indeterminate if only one positive band is detected. 